\title{
Globe
}

Revue internationale d'études québécoises

\section{Marcel Martel et Martin Pâquet, Langue et politique au Canada et au Québec. Une synthèse historique, Boréal, Montréal, 2010}

\section{Claude Verreault}

Volume 14, numéro 1, 2011

URI : https://id.erudit.org/iderudit/1005996ar

DOI : https://doi.org/10.7202/1005996ar

Aller au sommaire du numéro

Éditeur(s)

Globe, Revue internationale d'études québécoises

ISSN

1481-5869 (imprimé)

1923-8231 (numérique)

Découvrir la revue

Citer ce compte rendu

Verreault, C. (2011). Compte rendu de [Marcel Martel et Martin Pâquet, Langue et politique au Canada et au Québec. Une synthèse historique, Boréal, Montréal, 2010]. Globe, 14(1), 223-225. https://doi.org/10.7202/1005996ar d'utilisation que vous pouvez consulter en ligne.

https://apropos.erudit.org/fr/usagers/politique-dutilisation/ 


\section{Marcel Martel et Martin Pâquet}

Langue et politique au Canada et au Québec.

Une synthèse historique, Boréal, Montréal, 2010.

Selon la formulation des auteurs, cette étude «explore le rapport historique entre langue et politique au Canada et au Québec, du premier édit en matière linguistique adopté par le royaume de France en 1539 jusqu'à nos jours» (p. 12-13). À travers les six chapitres qui la constituent, elle relate les luttes menées par les francophones du Canada pour faire reconnaître leur langue et leurs droits linguistiques, ainsi que les divers contextes sociopolitiques dans lesquels elles ont eu lieu: "De la religion à la langue, 1539-1848" (p. 23-58); «Premières secousses linguistiques: les crises scolaires au Canada, 1848-1927» (p. 59-91); "Rien à signaler sur le front: du rappel du Règlement 17 à la commission Laurendeau-Dunton, 1927-1963» (p. 93-128); «Action-réaction: commissions d'enquête et agitation, 1963-1969» (p. 129170) ; «Agir: les lois linguistiques, 1969-1982» (p. 171-218); «Le droit et la langue, de 1982 à nos jours» (p. 219-271).

Le terminus a quo de cette synthèse historique aurait dû être mieux justifié. Dans la mesure où la colonisation de la Nouvelle-France n'a réellement commencé qu'au XVII ${ }^{\mathrm{e}}$ siècle, on s'explique en effet assez mal qu'il remonte aussi loin qu'à 1539, année de la promulgation par François ${ }^{\text {er }} \mathrm{du}$ célèbre édit de Villers-Cotterêts. Comme le sait quiconque connaît un tant soit peu l'histoire de la langue française, cette ordonnance, qui n'était du reste pas vraiment la première du genre à voir le jour en France, visait à faire remplacer le latin par le «langage maternel françois» dans les textes de nature administrative et juridique. Les autres interprétations que certains ont pu en proposer, notamment pour ce qui est de ses éventuelles conséquences sur les patois et les parlers régionaux, ne sont que des spéculations (à ce sujet, voir notamment Danièle Trudeau, 1993, et Geneviève Clerico, 1999, p. 149-151); en tout cas, elles ne permettent certainement pas de conclure que, «dès l'arrivée des premiers colons en Nouvelle-France, la monarchie favorise l'homogénéisation linguistique pour que le français devienne la langue commune de la colonie» (p. 12). Cette interprétation discutable explique à son tour que les auteurs aient endossé la thèse pourtant très critiquée du "choc des patois en Nouvelle-France» (p. 26-27), aujourd'hui réfutée par la plupart des spécialistes.

Dans le même ordre d'idées, les conclusions tirées des études linguistiques consultées ne sont pas toujours justes. Par exemple, rien dans 
l'ouvrage de Jean-Denis Gendron (2007) ne permet d'affirmer que «[d]e part et d'autre de l'Atlantique, les parlants français adoptent des accents différents à partir du milieu du XVIII siècle» (p. 27; les soulignés sont de moi).

À l'occasion, les auteurs font allusion à certains débats ayant porté sur la qualité de la langue, mais ils auraient mieux fait de s'en tenir seulement à ceux concernant son statut. D'une part, les commentaires relatifs à la qualité de la langue ne vont guère au-delà des idées reçues et ils tombent la plupart du temps à plat (voir p. 114-115, par exemple, où il est question de l'adoption, lors d'un congrès tenu en 1952, de diverses résolutions concernant la qualité du français à la radio, à la télévision et au cinéma); de l'autre, ils ne rendent pas bien compte des différents points de vue qui ont opposé ceux qui ont pris part à ces débats. Ainsi, la prise de position de Pierre Daviault reconnaissant l'existence légitime d'un "français canadien", distinct du français de France, n'était pas incompatible avec «l'obligation de bien parler la langue française» (p. 101) dont il souhaitait convaincre ses compatriotes, comme l'ouvrage le laisse malheureusement entendre. Il suffit de relire quelques-unes des nombreuses chroniques de langage que Daviault a fait paraître dans La Patrie entre 1952 et $1960^{1}$ pour constater qu'il n'a jamais voulu «imposer à [ses] concitoyens de langue française [sa] conception de la norme langagière» (p. 101). Lidée plutôt réaliste qu'il se faisait de la langue française - opposée ici à celle, fantasmée, de Victor Barbeau -, l'amenait tout naturellement à penser que le français usité au Canada, malgré et avec ses inévitables traits distinctifs, pouvait être d'aussi bonne qualité que celui employé en France. Il en va de même pour ce qui est du concept de «français international» (p. 134, et suivantes), que les auteurs semblent tenir pour acquis et comme allant de soi, ce qui est loin d'être le cas (à ce propos, voir notamment Klinkenberg, 2000).

La nécessaire frontière qui doit exister dans un ouvrage de ce genre entre la description des faits et leur interprétation n'est pas toujours respectée. Par exemple, les auteurs affirment que les politiques linguistiques mises sur pied au Québec entre 1969 et 1982 l'ont été "dans un souci constant du bien commun» (p. 188); or les nombreuses contestations auxquelles ces politiques ont donné lieu - et donnent encore lieu de nos jours montrent qu'il ne s'agit pas d'un fait, mais d'une opinion qui n'est d'ailleurs pas partagée par tous, bien au contraire. Par exemple encore, comment des organisations comme les centrales syndicales québécoises, l'Union des artistes

$$
+4 \div
$$

1. Ces chroniques sont accessibles sur le web (http://catfran.flsh.usherbrooke.ca/corpus/chroque/, consulté le 21 février 2011). 
et l'Union des écrivains québécois peuvent-elles objectivement être présentées comme des "regroupements nationalistes» (p. 236)? Que des membres de telles associations aient été des nationalistes notoires n'est-il pas une tout autre affaire?

Il aurait par ailleurs été utile de préciser le sens de certains termes récurrents dans l'ouvrage, à commencer par celui d'ordre symbolique, qui n'est pas toujours clair. Il en va de même pour ce qui est de rationalité managériale (p. 150), ainsi que de l'adjectif ethnoculturel, par exemple dans la phrase suivante: "Lorsque les promoteurs de la radio française présentent une demande pour exploiter une station, des groupes anglophones et ethnoculturels s'y opposent» (p. 114; les Canadiens anglais et les Canadiens français ne constituent-ils pas eux aussi des groupes «ethnoculturels»?).

Les références appelées dans le texte principal ne permettent pas de bien situer les sources dans leur contexte ni, le cas échéant, d'y retourner facilement. Elles se limitent la plupart du temps à la mention du nom, du titre ou de la fonction des auteurs dont les propos sont évoqués ou rapportés, un peu comme si cela suffisait à en garantir l'exactitude et la valeur; par exemple, "comme le constate la linguiste Chantal Bouchard" (p. 52), "comme le remarque l'historienne Lucia Ferretti" (p. 55) et "comme le notent le sociologue Fernand Dumont et l'historien Roberto Perin» (p. 55-56). Par ailleurs, bien des ouvrages fondamentaux, et qui se seraient pourtant avérés pertinents ici, sont absents de la bibliographie: Brunot (1966), Chaurand (dir.) (1999), Lusignan (2004), Noël (1990), Rey, Duval et Siouffi (2007), Oakes et Warren (2009), etc.

Enfin, la qualité de la langue et le style laissent parfois à désirer. Outre les inévitables coquilles, on relève aussi de curieuses constructions ( «la gronde des citoyens» (p. 160) pour «la grogne des citoyens», et «tirer leur aiguille du jeu» (p. 246) pour «tirer leur épingle du jeu», par exemple).

Tout compte fait, cette synthèse historique manque de rigueur et elle en décevra plus d'un. Elle pourra certes profiter à ceux qui sont peu familiers avec les luttes qu'ont dû mener les francophones du Canada pour faire reconnaître leur langue et leurs droits linguistiques, mais elle ne saurait s'imposer comme ouvrage de référence.

Claude Verreault Université Laval 